\title{
A study on Volumetric and Viscometric Properties for the Mixtures of DMF and Other Alcohols from Temperatures ranges 303.15K to 323.15K
}

\author{
Md. Helal Uddin*1,2, M. Z. H. Khan³, Md. Shahrul Islam², G.M. Arifuzzaman Khan ${ }^{2}$, Md. \\ Abdullah-Al-Muhit ${ }^{2}$, Jannatul Ferdaus ${ }^{4}$, Md. Abdul Momin ${ }^{2}$, and SK. Shahinur Rahman ${ }^{2}$ \\ ${ }^{1}$ Department of Materials Science, Faculty of Engineering, Osaka Prefecture \\ University, 1-1 Gakuen-Cho, Naka-Ku, Sakai, Osaka 599-8531, Japan \\ ${ }^{2}$ Faculty of Applied Science and Technology, Islamic University, \\ Kushtia-7003, Bangladesh \\ ${ }^{3}$ IMRAM, Tohoku University, Sendai, Japan \\ ${ }^{4}$ Youngone Central Laboratory, Youngone Hi-Tech Sportswear Ind. Ltd, Dhaka Export \\ Processing Zone, Savar, Dhaka, Bangladesh
}

\section{ABSTRACT}

\begin{abstract}
Densities, $\rho$, and viscosities, $\eta$, of four binary systems: $N, N$-dimethyl formamide (DMF) + 1-propanol, DMF + 2-propanol, DMF + butanol and DMF + 1-pentanol have been measured at five different temperatures ranging form $303.15 \mathrm{~K}$ to $323.15 \mathrm{~K}$ at an interval of $5 \mathrm{~K}$. Excess molar volumes were found to be negative over the entire concentration ranges. The negative excess molar volume decreases with the increase of chain length of alcohol, the magnitude follows the order DMF+ 1-propanol >, + 2-propanol >, + butanol >, + 1-pentanol. The change of viscosity has been found to be sensitive to the chain length of alcohols. Excess viscosities and Grunberg- Nissan interaction parameters have been found to be positive for DMF + 1-propanol and DMF + 2-propanol systems, and negative for other two systems DMF + butanol and $\mathrm{DMF}+1$-pentanol. The thermodynamic energy of activation; such as, positive $\Delta \mathrm{G}^{\# \mathrm{E}}$ each also compatible with the observation.
\end{abstract}

Keywords: Excess molar volume, Viscosity, Excess viscosity, $N, N$-dimethylformamide (DMF), Interaction parameter.

${ }^{\star}$ Corresponding author: Dr. Md. Zaved H. Khan \& Dr. Md. Helal Uddin (Department of Materials Science, Faculty of Engineering, Osaka Prefecture University, 1-1 Gakuen-Cho, Naka-Ku, Sakai, Osaka 599-8531, Japan). Mobile no: +818045660953, E-mail: uddindrhelal@gmail.com (M.H. Uddin); zaved.khan@yahoo.com (M. Z. H. Khan).

\section{Council for Innovative Research}

Peer Review Research Publishing System

\section{Journal of Advances in Natural Sciences}

Vol. 2, No. 2

editorjansonline@gmail.com

www.cirworld.com 


\section{Introduction}

The knowledge of chemical and physical properties of solvent systems containing two (or more) components is often required in theoretical studies [1-3] and for industrial and chemical processes at a wide range of temperatures [4-6]. The intensive properties may include density, viscosity (fluidity) as well as dielectric constant and refractive index. We have undertaken a study of thermochemical properties of four binary systems, in order to extend our knowledge and eventually to generalize or to improve empirical/theoretical correlation with composition.

The interpretation of nonideality is a fascinating area and a large number of contributions were made over the last decade. Solution theory is still far from adequate to account for solution nonidealities in terms of the properties of the constituent molecules. The experimental data on macroscopic properties such as excess molar volumes, excess viscosities, surface tension, and refractive index often provide valuable information for the understanding of the nature of homo and heteromolecular interactions. Alcohol-amide solutions are of practical importance. DMF to some extent is associated by means of dipole-dipole interactions. Significant structural effects are absent due to the lack of hydrogen bonds. Therefore, it acts as an aprotic protophilic solvent of moderately high dielectric constant $(=36.71)$ of molecules with a large dipole moment (ì=3.8 D) at $298.15 \mathrm{~K}$ [7]. Because of its miscibility with almost all common polar and nonpolar solvents [8-12] it is classified as so-called super solvent. A DMF molecule can interact with an alkanol molecule by virtue of better hydrogen bond acceptor ability of its oxygen atom, resulting in structural and packing effects. Volumetric, viscometric and related thermodynamic properties for the mixtures containing DMF were recently reported in the literature [13-20].

In our previous paper [7] described some physical properties of methanol, ethanol and 2-propanol at temperatures from $303.15 \mathrm{~K}$ to $323.15 \mathrm{~K}$. Recently M. Kondaiah et.al [21] measured the densities, and viscosities of mixtures of propionic acid with equimolar mixtures of DMF + methanol/ethanol/1-propanol, over the entire composition range of propionic acid and including the pure liquids, have been measured at the temperatures $T / K=303.15,313.15$, and 323.15 . Therefore, to make a correlation in present paper highlights the molar volumes, excess molar volumes, viscosities, excess viscosities, excess enthalpy of activation, excess entropy of activation, and excess free energy of activation data of DMF $+1-$ propanol, + 2-propanol, + butanol, and + 1-pentanol systems over the whole range of compositions at five different temperatures ranges from $303.15 \mathrm{~K}$ to $323.15 \mathrm{~K}$.

\section{Experimental}

N,N-dimethyl formamide (DMF), 1-propanol, 2-propanol, butanol and pentanol was purchased from Merck, Germany and used without further purification. Binary mixtures were prepared by mass in air tight Stoppard glass bottle. Density was measured by density measurement bottle using an analytical balance (LIBROR EX-180, Shimadzu, Japan) with a readability of $0.0001 \mathrm{~g}$. Care was taken to avoid evaporation and solvent contamination during preparation of mixtures. The mole fraction was accurate up to the fourth place of decimal.

An Ostwald U-tube viscometer A type (Germany) with sufficiently long efflux time was used for viscosity measurements. An electronic digital stopwatch with a readability of $\pm 0.01 \mathrm{~s}$ was used for the flow time measurements. At least three repetitions of each data point obtained were reproducible to $\pm 0.05 \mathrm{~s}$ and the results were averaged. All measurements were carried out in a thermostatic water bath (TE-8A, Techne, Germany) controlled to $\pm 0.01 \mathrm{~K}$. The purity of the solvents were assessed by comparing their measured density and viscosity data, in which a)

viscosity and density of DMF and butanol, b) density of 1-propanol and 2-propanol were in good agreement but c) viscosity of 1-propanol, 2-propanol and 1-pentanol, and d) density of 1-pentanol were not in good agreement with the literature value [22-27] as can be seen in Table 1.

\section{Results and Discussion}

The excess molar volumes, $V_{\mathrm{m}}^{\mathrm{E}}$ were calculated using the equation

$$
V_{\mathrm{m}}^{\mathrm{E}}=\left[\left(\mathrm{x}_{1} \mathrm{M}_{1}+\mathrm{x}_{2} \mathrm{M}_{2}\right) / \rho_{12}-\left(\mathrm{x}_{1} \mathrm{M}_{1} / \rho_{1}+\mathrm{x}_{2} \mathrm{M}_{2} / \rho_{2}\right)\right]
$$

where $x_{1}, M_{1}$ and $\rho_{1}$ are the mole fraction, molar mass and density of pure DMF, $x_{2}, M_{2}$ and $\rho_{2}$ are the corresponding quantities for alkanol in each system. $\rho_{12}$ is the density of the corresponding binary solution. The variation of $V_{\mathrm{m}}^{\mathrm{E}}$ with mole fraction of DMF at different temperatures are shown graphically in Figs. 1, 2, 3 and 4 for the DMF +1 -propanol, +2 propanol, + butanol and +1-pentanol systems respectively.

Examination of Figs. 1-4 reveals that

(i) For DMF + 1-propanol system (Fig. 1) the excess molar volumes $V_{\mathrm{m}}^{\mathrm{E}}$ are negative throughout the whole range of composition except 0.9 mole fraction of DMF with minima at 0.3 mole fraction of DMF. The effect of temperature on $V_{\mathrm{m}}^{\mathrm{E}}$ shows a definite trend, i.e., the negative values increase with the rise of temperature and mole fraction of DMF. 
(ii) On addition of DMF + 2-propanol (Fig. 2), DMF + butanol system (Fig. 3), DMF + 1-pentanol system (Fig. 4) the excess molar volumes $V_{\mathrm{m}}^{\mathrm{E}}$ are negative with minima at 0.4 mole fraction of DMF. The $\left(\delta V_{\mathrm{m}}^{\mathrm{E}} / \delta \mathrm{T}\right) \mathrm{p}$ is found to be negative over the entire range of composition.

The deviation of viscosity from the ideal mixture values (i.e. excess viscosity) can be calculated using the following equation for two component system [28-32].

$$
\eta^{E}=\eta_{12}-\exp \left(x_{1} \ln \eta_{1}+x_{2} \ln \eta_{2}\right)
$$

Grunberg and Nissan proposed an equation [33] relating the viscosity and strength of interaction as follows

$$
\ln \eta=x_{1} \ln \eta_{1}+\left(1-x_{1}\right) \ln \eta_{2}+x_{1} x_{2} \varepsilon
$$

where, $\eta_{12}, \eta_{1}$, and $\eta_{2}$ are the viscosity of binary solution, component 1 and component 2 respectively. The variations of $\eta^{E}$ with mole fraction of DMF at different temperatures are shown graphically in Figs. 5, 6, 7 and 8 for the DMF + 1-propanol, + 2-propanol, + butanol, + pentanol systems. Examination of Figs. 5 to $\mathbf{8}$ shows the following characteristics:

(i) The excess viscosities at different temperatures for the DMF + 1-propanol system (Fig. 5) are positive throughout the whole range of composition, the maxima occur between 0.3 and 0.4 mole fractions of DMF.

(ii) For the DMF + 2-propanol system (Fig. 6), the excess viscosities are positive over the entire range of composition and the maxima occur at 0.4 mole fraction of DMF.

(iii) The excess viscosities of the DMF + butanol system (Fig. 7) are negative throughout the entire concentration range and the magnitude is comparatively large.

(iv) The excess viscosities of the DMF + pentanol system (Fig. 8) are also negative throughout the whole concentration range with minima at 0.4 mole fraction of DMF.

Enthalpy of activation, $\Delta H^{\#}$ and entropy of activation, $\Delta S^{\#}$ for viscous flow may be obtained from the Erying equation for viscosity as:

$$
\ln \left(\eta V_{m} / h N\right)=-\Delta S^{\#} / R+\Delta H^{\#} / R T
$$

For each individual mixtures, when $\ln \left(n V_{m} / h N\right)$ is plotted against $1 / T$, a straight line is expected, from the slope and intercept of which $\Delta H^{\#}$ and $\Delta S^{\#}$ can be calculated respectively. The free energy of activation, $\Delta G^{\#}$ for viscous flow was then obtained using the thermodynamic relation,

$$
\Delta G^{\#}=\Delta H^{\#}-T \Delta S^{\#}
$$

The excess enthalpy of activation $\Delta \mathrm{H}^{\# \mathrm{E}}$, entropy of activation, $\Delta \mathrm{S}^{\# \mathrm{E}}$, and free energy of activation $\Delta \mathrm{G}^{\# \mathrm{E}}$ were calculated by using the following relation,

$$
y^{E}=y-\left(x_{1} y_{1}+x_{2} y_{2}\right)
$$

Where, $y$ is the thermodynamic property of the solution. $y_{1}$ and $y_{2}$ are the properties of the pure components forming the binary mixtures, $x_{1}$ and $x_{2}$ are the respective mole fractions.

Fig. 9: Shows the variation of excess enthalpy, $\Delta H^{\# E}$, and excess entropy, $T \Delta S^{\# E}$ as a function of mole fraction of $D M F$ for (DMF+1-propanol) system. The pattern of these curves is almost similar and show both positive and negative values with different magnitude. The positive values of $\Delta S^{\# E}$ are accounted for by the destruction of highly associated alcohol, and negative values of $\Delta S^{\# E}$ are accounted for by the formation of DMF alcohol complex, in the activation process.

Fig. 10: shows the plot of excess free energy of activation, $\Delta G^{\# E}$ as a function of DMF mole fraction for (DMF+1-propanol) system at five different temperatures under investigations. The values of $\Delta G^{\# E}$ are found to be positive over the entire range of composition with maxima at 0.4 mole fraction of DMF. The positive excess values signify that the species formed in the activated state experience more resistance to flow than what should be expected.

Fig. 11, 12 and 13: Show the graphical representation of excess entropy, $T \Delta S^{\# E}$ as a function of mole fraction of DMF for DMF + 2-propanol, + butanol, +1-pentanol system respectively. The curves 11 and 12 follow similar pattern and the values are both negative and positive. But the curve 13 shows only negative values. The negative values of $\mathrm{T} \Delta \mathrm{S}^{\# \mathrm{E}}$, indicated that in the activated state of the flow process, the species formed are structurally more ordered than in ground state.

Fig. 14, 15 and 16: Show the representation of the plots of excess free energy, $\Delta G^{\# E}$ as a function of DMF mole fraction at five different temperatures under investigations for DMF + 2-propanol, + butanol, + 1-pentanol system respectively. The values for 2-propanol are positive while the values for butanol and pentanol are negative over the entire composition range. For a low concentration of DMF 0.1 mole fraction we found only a positive value in DMF + 1-pentanol system.

In order to compare the excess free energy, $\Delta G^{\# E}$ of the systems in which a particular DMF is fixed as a common component and alcohols are varied, it can be seen that

(i) Excess free energies of mixtures DMF + 1-propanol, + 2-propanol are positive for the entire range of composition.

(ii) Excess free energies of mixtures DMF + butanol, +1-pentanol are negative for whole range of composition except 0.1 mole fraction of DMF for DMF +1 -pentanol system. 
The sign of $\mathrm{V}_{\mathrm{m}}{ }^{\mathrm{E}}$ of a system depends upon the relative magnitude of expansion and contraction of the two liquids due to mixing. In case of positive values of $V_{\mathrm{m}}^{\mathrm{E}}$ are responsible for:

a) Disruption of the structure of one or both of the components in the solution, which is the loss of dipolar association between the molecules.

(b) The geometry of molecular structure which does not favor fitting of the molecules with each other.

(c) Steric hindrance of the molecules.

The negative values of $V_{\mathrm{m}}^{\mathrm{E}}$ may explain as (Fig. 1-4):

(a) Chemical interaction between constituent molecules such as hetero-molecular association through the formation of $\mathrm{H}$-bond, often termed as strong specific interaction.

(c) Accommodation of molecules of one component into the interstitial positions of the structural network of molecules of the other component.

(d) Geometry of the molecular structure that favors fitting of the component molecules with each other. The variations of the excess molar volumes in the present investigation are negative over the entire range mole fraction except DMF +1 propanol system at higher concentration of DMF. The presence of strong interaction is due to the hydrogen bonding $(\mathrm{O}---$ $\mathrm{H}-\mathrm{O}-)$ between the carbonyl group $(-\mathrm{C}=\mathrm{O})$ of amide molecules and the hydroxyl group $(-\mathrm{OH})$ of alcohol molecules. Moreover, all of the components of the liquid mixtures studied are polar in nature having diploe moments of : 1-propanol $\mu$ $=1.58 \mathrm{D}, N, N$-dimethylformamide $\mu=3.82 \mathrm{D}, 2$-propanol $\mu=1.560 \mathrm{D}$, butanol $\mu=1.66 \mathrm{D}, 1$-pentanol $\mu=1.65 \mathrm{D}$ [47]. In addition, physical interactions, such as geometrical fitting of smaller molecules into the voids created by the larger molecules is also favorable for the present systems. On the other hand, alcohol molecules undergo self- and crossassociation because of the presence of hydrogen bonds [19,31].

Mixing of DMF with an alcohol will induce changes in hydrogen bonding (in the alkanol) and dipolar interactions (in the DMF). On addition of DMF to the pure alcohol the self-association will be disrupted partly or fully and new $\mathrm{H}$-bonds between alcohol and DMF will be formed. At the same time, segmental inclusion of DMF into the vacant spaces left in the structural network of alcohol may also occur.

Aso, volume contraction of DMF +1-propanol is expected to be greater than the systems containing other alcohols. However, as the chain length of alcohols increases, the size effect consequently decreases. The negative contribution to $V_{\mathrm{m}}^{\mathrm{E}}$ due to this effect is therefore expected to be in the order: DMF+1-propanol $>,+2$-propanol $>,+$ butanol $>,+1$ pentanol.

The analysis of the previous works shows that the negative values of $V_{\mathrm{m}}^{\mathrm{E}}$ decrease with the increase of the chain length of alkanol [7]. The results of our present investigation of DMF + alkanols $\left(C_{3}-C_{5}\right)$ binary mixtures were in conformity with the results of these reported investigations. From Figs. $\mathbf{1}$ to $\mathbf{4}$, it is seen that the value of negative excess molar volumes increases with the rise of temperature, meaning that $\left(\delta V_{\mathrm{m}}^{\mathrm{E}} / \delta \mathrm{T}\right) \mathrm{p}$ is negative. This may be accounted for in the following manner.

A fundamental difference in the behavior of excess viscosities observed is that the values are found to be positive for DMF +1- propanol, 2- propanol, whereas they are negative for systems consisting of DMF+ butanol, pentanol. Further, the excess viscosities of these systems, regardless of their sign, can be generalized by saying that the magnitude of the values, $\left|\eta^{E}\right|$, decreases on increase of temperature as observed from Figs. $\mathbf{5}$ to $\mathbf{8}$. The positive excess viscosities (as in Fig. 5 and 6) and positive interaction parameters for the DMF + 1- propanol, +2-propanol systems indicate strong interaction. Masegosa et al. [34] reported positive values of interaction parameters corresponding to systems with negative excesses molar volumes. This consistent with our results. Also the negative excess viscosities (as in Figs.7 and 8 ) and negative interaction parameters for the systems DMF + butanol, + 1-pentanol indicate weak interaction. The mixtures of associated molecules that the main reason for a positive $V_{\mathrm{m}}^{\mathrm{E}}$, and a negative $\eta^{\mathrm{E}}$ may be the disruption of the associated molecules and the main factor for a negative $V_{\mathrm{m}}^{\mathrm{E}}$, and a positive $\eta^{\mathrm{E}}$ may be the association or compound formation between the components. Positive values of $\eta^{E}$ are observed for the systems where specific interaction causes complex formation, and negative values of $\eta^{E}$ are observed for systems of different molecular size in which the dispersion forces are dominant.

Gracia et al. 1991 [35] observed that for two pyrolidone + 1-alkanols, excess free energies were found to be positive in case of methanol and negative with higher alcohols. The negative value of $\Delta \mathrm{G}^{\# \mathrm{E}}$ for $\mathrm{DMF}+$ butanol and DMF + 1-pentanol show agreement with above [35] observation. The sign of, $\Delta \mathrm{G}^{\# \mathrm{E}}$ for a system is regarded to be more reliable criterion as to tell about the strength of interaction. Thus, if $\Delta \mathrm{G}^{\mathrm{ft}}$ is positive the interaction between the components in 
binary system is strong, the strength of interaction, however, depends upon the magnitude of, $\Delta \mathrm{G}^{\# \mathrm{E}}$. If on the other hand, the sign of $\Delta \mathrm{G}^{\# \mathrm{E}}$ is negative the interaction between the components molecule is weak or very weak. The positive values of $\Delta G^{\sharp E}$ for DMF + 1-propanol, + 2-propanol over the entire range of composition indicating that the interaction of DMF with 1-propanol and with 2-propanol is strong. The positive $\Delta \mathrm{G}^{\# E}$ can be viewed as the increase of the energy barrier that the species in the solution are to surmount in the flow process. The barrier height is increased due to the formation of associated compound through $\mathrm{H}$-bonding between DMF and 1-propanol, and also between DMF and 2-propanol. The negative $\Delta G^{\# E}$ for DMF + butanol, + 1-pentanol can be viewed as the reduction of the energy barrier that the species in the solution are to surmount in the flow process the barrier height is reduced for the reduction of surface of the activated complex by the segmental inclusion of DMF into polymolecular alcohol aggregates. All the above positive and negative excess free energy results for the four systems

are quite compatible with the positive and negative excess viscosity and interaction parameters as discussed above.

\section{Conclusion}

Volumetric, viscometric and their related thermodynamic properties for the four binary systems of DMF + 1-propanol, DMF + 2-propanol, DMF + butanol and DMF + 1-pentanol are calculated and represented graphically. The sign of $V_{m}^{E}$ of a system depends upon the relative magnitude of expansion and contraction of the two liquids due to mixing. The negative contribution to $V_{m}^{E}$ represents, in the order: DMF+ 1-propanol >, + 2-propanol >, + butanol >, + 1-pentanol. The positive excess viscosities and positive interaction parameters for the DMF +1 - propanol, +2 -propanol systems indicate strong interaction and the negative excess viscosities and negative interaction parameters for the systems DMF + butanol, $+1-$ pentanol indicate weak interaction. The thermodynamic excess properties (e.g. $V^{E}, \eta^{\mathrm{E}}, \Delta H^{\# \mathrm{E}}, \Delta S^{\# \mathrm{E}}$, and $\Delta G^{\# \mathrm{E}}$ ) were correlated satisfactorily by the polynomial equation for all the four alcohol- DMF mixtures at all temperatures. The sign of $\Delta G^{\# E}$ for a system is regarded to be more reliable criterion as to tell about the strength of interaction. Thus, if $\Delta \mathrm{G}^{\# E}$ is positive the interaction between the components in binary system is strong, the strength of interaction, however, depends upon the magnitude of, $\Delta \mathrm{G}^{\# \mathrm{E}}$. If on the other hand, the sign of $\Delta \mathrm{G}^{\# E}$ is negative the interaction between the components molecule is weak or very weak.

\section{References}

1. Scilipoti, J., Cismondi, M., Brignole, E.A.: Prediction of physical properties for molecular design of solvents. Fluid Phase Equilib. 362, 74-80 (2014).

2. Guha, C., Das, B.: Ion-association and solvation behavior of ammonium and potassium thiocyanates in 2methoxyethanol+water mixed solvent media at different temperatures. J. Mol. Liq. 193, 132-138 (2014).

3. Matsuda, H., Hirota, Y., Kurihara, K., Tochigi, K., Ochi, K.: Liquid-liquid equilibria containing fluorous solvents as environmentally benign solvent. Fluid Phase Equilib. 357, 71-75 (2013).

4. Santiago, R.S., Aznar, M.: Liquid-liquid equilibrium in ternary ionic liquid systems by UNIFAC: New volume, surface area and interaction parameters. Part II. Fluid Phase Equilib. 303, 111-114 (2011).

5. Franchini, G.C., Marchetti, A., Tagliazucchi, M., Tassi, L., Tosi, G.: Ethane-1,2-diol?2-methoxyethanol solvent system. Dependence of the relative permittivity and refractive index on the temperature and composition of the binary mixture. J. Chem. Soc. Faraday Trans. 87, 2583 (1991).

6. Nikam, P.S., Jadhav, M.C., Hasan, M.: Density and Viscosity of Mixtures of Dimethyl Sulfoxide + Methanol, +Ethanol, +Propan-1-ol, +Propan-2-ol, +Butan-1-ol, +2-Methylpropan-1-ol, and +2-Methylpropan-2-ol at 298.15 K and $303.15 \mathrm{~K}$. J. Chem. Eng. Data. 41, 1028-1031 (1996).

7. Bhuiyan, M.M.H., Uddin, M.H.: Excess molar volumes and excess viscosities for mixtures of N,N-dimethylformamide with methanol, ethanol and 2-propanol at different temperatures. J. Mol. Liq. 138, 139-146 (2008).

8. Davis, P.S., Kilpatrick, J.E.: Entropy, related thermodynamic properties, and structure of methylisocyanate. J. Chem. Thermodyn. 58, 134-141 (2013).

9. Chen-Ho Tung, Li-Zhu Wu: A novel type of molecular assembly: aggregates formed by molecules with polar chains in nonpolar solvents. Chem. Phys. Lett. 244, 157-163 (1995).

10. Lévay, B.: Temperature dependence of the positronium yields in polar and nonpolar pure liquids; an experimental test of a phenomenological model. Chem. Phys. 303, 97-100 (2004).

11. Mahapatra, R., Ray, S.K.: Intermolecular interaction in the binary mixtures of ketones with nonpolar molecules. J. Mol. Liq. 193, 87-93 (2014).

12. Tekin, N., Cebe, M., Tarımcı, Ç.: Polarizabilities and dipole moments of benzaldehyde, benzoic acid and oxalic acid in polar and nonpolar solvents. Chem. Phys. 300, 239-246 (2004).

13. Tsierkezos, N.G., Filippou, A.C.: Thermodynamic investigation of N,N-dimethylformamide/toluene binary mixtures in the temperature range from 278.15 to $293.15 \mathrm{~K}$. J. Chem. Thermodyn. 38, 952-961 (2006). 
14. Godhani, D.R., Dobariya, P.B., Sanghani, A.M., Mehta, J.P.: Thermo-physical properties of 1,3,4-oxadiazole derivatives in pure solvents. J. Chem. Thermodyn. 57, 436-444 (2013).

15. Godhani, D.R., Dobariya, P.B., Sanghani, A.M., Jogel, A.A., Mehta, J.P.: Thermo-acoustical studies of 1,3,4oxadiazole as binary mixture at three different temperatures. J. Chem. Thermodyn. 70, 73-80 (2014).

16. Shekaari, H., Bezaatpour, A., Elhami-Kalvanagh, R.: Effect of an ionic liquid on the volumetric behavior of tetradentate N2O2 type Schiff bases in DMF at $\mathrm{T}=(308.15$ to 328.15)K. J. Chem. Thermodyn. 51, 114-119 (2012).

17. Mohammad, A.A., Alkhaldi, K.H.A.E., AlTuwaim, M.S., Al-Jimaz, A.S.: Viscosity and surface tension of binary systems of $\mathrm{N}, \mathrm{N}$-dimethylformamide with alkan-1-ols at different temperatures. J. Chem. Thermodyn. 56, 106-113 (2013).

18. Nain, A.K.: Densities, ultrasonic speeds, viscosities and excess properties of binary mixtures of methyl methacrylate with N,N-dimethylformamide and N,N-dimethylacetamide at different temperatures. J. Chem. Thermodyn. 60, 105116 (2013).

19. Baluja, S., Solanki, A., Kachhadia, N.: Studies on Thermodynamic Properties of Some Imidazolinone Derivatives in DMF at 308.15 K. Chinese J. Chem. Eng. 18, 306-311 (2010).

20. Jia, Z., Hu, X., Cheng, W., Liu, J., Guo, A., Fang, G.: Homotactic enthalpic pairwise interactions of four deoxynucleosides (dU, dC, dG, dT) in dimethylformamide (DMF)+water mixtures at 298.15K. Thermochim. Acta. 549, 148-157 (2012).

21. Kondaiah, M., Sreekanth, K., Sravana Kumar, D., Krishna Rao, D.: Volumetric and Viscometric Properties of Propanoic Acid in Equimolar Mixtures of N,N-dimethyl Formamide + Alkanols at $\mathrm{T} / \mathrm{K}=303.15,313.15$, and 323.15. J. Solution Chem. 42, 494-515 (2012).

22. Alonso, V., González, J.A., de la Fuente, I.G., Cobos, J.C.: Dielectric and refractive index measurements for the systems 1-pentanol+2,5,8,11,14-pentaoxapentadecane, or for 2,5,8,11,14-pentaoxapentadecane+octane at (293.15303.15)K. Thermochim. Acta. 551, 70-77 (2013).

23. Contreras S, M.: Densities and Viscosities of Binary Mixtures of 1,4-Dioxane with 1-Propanol and 2-Propanol at (25, 30, 35, and 40) ${ }^{\circ} \mathrm{C}$. J. Chem. Eng. Data. 46, 1149-1152 (2001).

24. Clará, R.A., Marigliano, A.C.G., Campos, V. del V., Sólimo, H.N.: Density, viscosity, vapour-liquid equilibrium, excess molar enthalpy, and their correlations of the binary system [1-pentanol+R-(+)-limonene] over the complete concentration range, at different temperatures. Fluid Phase Equilib. 293, 151-156 (2010).

25. Boned, C., Baylaucq, A., Bazile, J.P.: Liquid density of 1-pentanol at pressures up to $140 \mathrm{MPa}$ and from 293.15 to 403.15K. Fluid Phase Equilib. 270, 69-74 (2008).

26. Bhuiyan, M.M.H., Ferdaush, J., Uddin, M.H.: Densities and viscosities of binary mixtures of \{dimethylsulfoxide+aliphatic lower alkanols $(\mathrm{C} 1-\mathrm{C} 3)$ \} at temperatures from $\mathrm{T}=303.15 \mathrm{~K}$ to $\mathrm{T}=323.15 \mathrm{~K}$. J. Chem. Thermodyn. 39, 675-683 (2007).

27. Alonso, V., González, J.A., García de la Fuente, I., Cobos, J.C.: Dielectric and refractive index measurements for the systems 1-pentanol + octane, or + dibutyl ether or for dibutyl ether + octane at different temperatures. Thermochim. Acta. 543, 246-253 (2012).

28. Al-Hayan, M.N.M., Abdul-latif, A.-H.M.: Excess molar volumes and viscosities of (1,1,2,2-tetrabromoethane+1alkanols) at $\mathrm{T}=(293.15$ and 303.15) K. J. Chem. Thermodyn. 38, 68-74 (2006).

29. Iloukhani, H., Habibi, M., Khanlarzadeh, K.: Excess molar volumes, viscosity deviations and excess thermal expansion coefficients for binary and ternary mixtures consist of diethylketone+2-butanol+ethylchloroacetate at (298.15, 308.15 and 318.15) K. Thermochim. Acta. 563, 67-71 (2013).

30. Jeevanandham, P., Kumar, S., Periyasamy, P.: Densities, viscosities, refractive indices and excess properties of ortho- and meta-chloroaniline with 2-alkoxyethanols at 303.15K. J. Mol. Liq. 188, 203-209 (2013).

31. Mariano, A., Postigo, M.: Excess molar volume and viscosity study for the ternary system tetrahydrofuran (1)+1chlorobutane (2)+2-butanol (3) at 283.15, 298.15 and 313.15K. Fluid Phase Equilib. 239, 146-155 (2006).

32. Postigo, M., Mariano, A., Mussari, L., Camacho, A., Urieta, J.: Excess molar volume and viscosity study for the ternary system tetrahydrofuran (1) + 1-chlorobutane (2) + 1-butanol (3) at 283.15, 298.15 and 313.15 K. Fluid Phase Equilib. 207, 193-207 (2003).

33. GRUNBERG, L., NISSAN, A.H.: Mixture law for viscosity. Nature. 164, 799 (1949).

34. Masegosa, R.M., Llorente, M.A., Prolongo, M.G., Hern ndez-Fuentes, I., Horta, A.: Swelling equilibrium and preferential sorption of crosslinked poly(methyl methacrylate) in the mixture acetonitrile $+n$-butanol. Colloid Polym. Sci. 262, 862-866 (1984).

35. Garcia, B., Herrera, C., Leal, J.M.: Shear viscosities of binary liquid mixtures: 2-pyrrolidinone with 1-alkanols. J. Chem. Eng. Data. 36, 269-274 (1991). 
36. Thirumaran, S., Ramesh, J.: Acoustic and excess thermodynamical studies on 1-alkanols with DMA in cyclohexanone at different temperatures. Rasayan J. Chem. 2, 733-739 (2009).

37. El-Dossoki, F.I.: Refractive Index and Density Measurements for Selected Binary Protic-Protic, Aprotic-Aprotic, and Aprotic-Protic Systems at Temperatures from 298.15 K to 308.15 K. J. Chinese Chem. Soc. 54, 1129-1137 (2007).

38. Ruostesuo, P., Mattila, T.: Thermodynamic properties of binary mixtures containing sulfur amide. 2. Excess molar volumes of 1,4-dioxane $+\mathrm{N}, \mathrm{N}$-dimethylmethanesulfinamide and 1,4-dioxane $+\mathrm{N}$-methylmethanesulfinamide. J. Chem. Eng. Data. 32, 241-243 (1987).

39. Xu, L., Lin, G., Wang, X., Lin, R.: Densities and volumetric properties of 2-chloroethanol with N,N-dimethylformamide and water at different temperatures. J. Mol. Liq. 123, 130-133 (2006).

40. Vittal Prasad, T.E., Mythili, R., Nirmala, G.S., Prasad, D.H.L.: Densities and Viscosities of the Binary Mixtures of Chloroethylenes with Some Aliphatic Alcohols. J. Chem. Eng. Data. 47, 68-71 (2002).

41. Saleh, M.A., Uddin, M.H.: Viscosity and Thermodynamics of Viscous Flow of the Systems, 1-Propanol + Formamide, + N -Methylformamide, + N,N -Dimethylformamide. Phys. Chem. Liq. 37, 701-718 (1999).

\section{Figure captions}

Fig. 1: Excess molar volume, $V_{\mathrm{m}}^{\mathrm{E}} / \mathrm{cm}^{3}$. $\mathrm{mol}^{-}$of DMF $\left(x_{1}\right)$ and 1-propanol $\left(x_{2}\right)$ system at different temperatures 303.15-323.15K.

Fig. 2: Excess molar volume, $V_{\mathrm{m}}^{\mathrm{E}} / \mathrm{cm}^{3}$. mol of DMF $\left(x_{1}\right)$ and 2-propanol $\left(x_{2}\right)$ system at different temperatures 303.15$323.15 \mathrm{~K}$

Fig. 3: Excess molar volume, $V_{\mathrm{m}}^{\mathrm{E}} / \mathrm{cm}^{3} \cdot \mathrm{mol}^{-1}$ of DMF $\left(x_{1}\right)$ and butanol $\left(x_{2}\right)$ system at different temperatures 303.15$323.15 \mathrm{~K}$.

Fig. 4: Excess molar volume, $V_{\mathrm{m}}^{\mathrm{E}} / \mathrm{cm}^{3} \cdot \mathrm{mol}^{-1}$ of DMF $\left(x_{1}\right)$ and 1-penanol $\left(x_{2}\right)$ system different temperatures 303.15$323.15 \mathrm{~K}$.

Fig. 5: Excess viscosity, $\mathrm{\eta}^{\mathrm{E}} / \mathrm{mP}$ of DMF $\left(x_{1}\right)$ and 1-propanol $\left(x_{2}\right)$ system at different temperatures 303.15-323.15K.

Fig. 6: Excess viscosity, $\mathrm{n}$ /mP of DMF $\left(x_{1}\right)$ and 2-propanol $\left(x_{2}\right)$ system at different temperatures 303.15-323.15K.

Fig. 7: Excess viscosity, $\eta^{\mathrm{E}} / \mathrm{mP}$ of $\mathrm{DMF}\left(x_{1}\right)$ and Butanol $\left(x_{2}\right)$ system at different

temperatures 303.15-323.15K.

Fig. 8: Excess viscosity, $\eta^{\mathrm{E}} / \mathrm{mP}$ of $\mathrm{DMF}\left(x_{1}\right)$ and 1-pentanol $\left(x_{2}\right)$ system at different $323.15 \mathrm{~K}$.

Fig. 9: Excess entropy of activation, $\mathrm{T} \Delta \mathrm{S}^{\# \mathrm{E}} / \mathrm{K} . \mathrm{J} \mathrm{mol}^{-1}$ of $\mathrm{DMF}\left(x_{1}\right)$ and 1-propanol $\left(x_{2}\right)$ system temperatures 303.15 temperatures 303.15-323.15K.

Fig. 10: Excess free energy of activation $\Delta \mathrm{G}^{\# E} / \mathrm{K} . J \cdot \mathrm{mol}^{-1}$ of DMF $\left(x_{1}\right)$ and 1-propanol $\left(x_{2}\right)$ at different temperatures $303.15-323.15 \mathrm{~K}$.

Fig. 11: Excess entropy of activation, $\mathrm{T} \Delta \mathrm{S}^{\# \mathrm{E}} / \mathrm{K} . \mathrm{J} \cdot \mathrm{mol}^{-1}$ of DMF $\left(x_{1}\right)$ and 2-propanol $\left(x_{2}\right)$ temperatures 303.15-323.15K.

Fig. 12: Excess entropy of activation, $\mathrm{T} \Delta \mathrm{S}^{\# \mathrm{E}} / \mathrm{K} \cdot \mathrm{J} \cdot \mathrm{mol}^{-1}$ of DMF $\left(x_{1}\right)$ and butanol $\left(x_{2}\right)$ system temperatures 303.15-323.15K.

Fig. 13: Excess entropy of activation, $\mathrm{T} \Delta \mathrm{S}^{\# \mathrm{E}} / \mathrm{K} . \mathrm{J} \cdot \mathrm{mol}^{-1}$ of $\mathrm{DMF}\left(x_{1}\right)$ and 1-pentanol $\left(x_{2}\right)$ system temperatures 303.15-323.15K.

Fig. 14: Excess free energy of activation $\Delta \mathrm{G}^{\# \mathrm{E}} / \mathrm{K} \cdot \mathrm{J} \cdot \mathrm{mol}^{-1}$ of $\mathrm{DMF}\left(x_{1}\right)$ and 2-propanol $\left(x_{2}\right)$ temperatures 303.15-323.15K.

Fig. 15: Excess free energy of activation $\Delta \mathrm{G}^{\# \mathrm{E}} / \mathrm{K} . \mathrm{J} \cdot \mathrm{mol}^{-1}$ of DMF $\left(x_{1}\right)$ and 1-butanol $\left(x_{2}\right)$ temperatures 303.15-323.15K.

Fig. 16: Excess free energy of activation $\Delta \mathrm{G}^{\# \mathrm{E}} / \mathrm{KJmol}^{-1}$ of DMF $\left(x_{1}\right)$ and 1-pentanol $\left(x_{2}\right)$ temperatures $303.15-323.15 \mathrm{~K}$.

system at different

system at different

at different

at different

system at different

system at different

system at different 
Table 1: Comparison of densities, $\left(\rho / \mathrm{g} \cdot \mathrm{cm}^{-3}\right)$, and viscosities, $\left(\mathrm{\eta}^{\mathrm{E}} / \mathrm{mP}\right)$, of pure liquids with literature data at different temperatures.

\begin{tabular}{|c|c|c|c|c|c|c|}
\hline \multirow[t]{2}{*}{ Component } & \multirow[t]{2}{*}{ property } & \multicolumn{5}{|c|}{ Temperature/K } \\
\hline & & 303.15 & 308.15 & 313.15 & 318.15 & 323.15 \\
\hline \multirow[t]{7}{*}{ DMF } & $\rho$ & 0.9407 & 0.9367 & 0.9312 & 0.9268 & 0.9222 \\
\hline & & $0.9394^{\prime}$ & $0.9342^{\prime}$ & $0.9301^{\prime}$ & $0.9253^{\prime}$ & $0.9201^{\prime}$ \\
\hline & & $0.9398^{6}$ & $0.935717^{37}$ & $0.9302^{41}$ & $0.925986^{37}$ & $0.921141^{37}$ \\
\hline & & $0.93793^{36}$ & $0.9351^{56}$ & $0.92653^{36}$ & & \\
\hline & & & & $0.93098^{5 /}$ & & \\
\hline & $\eta$ & 7.5097 & 7.03745 & 6.5795 & 6.2559 & 5.9518 \\
\hline & & $7.753^{\prime}$ & $7.329^{\prime}$ & $6.9^{\prime}$ & $6.53^{\prime}$ & $6.14^{\prime}$ \\
\hline \multirow[t]{5}{*}{ 1-Propanol } & $\rho$ & 0.7832 & 0.7792 & 0.7753 & 0.7706 & 0.7661 \\
\hline & & $0.79601^{23}$ & 0.792 & $0.7871^{20}$ & $0.7850^{41}$ & $0.7789^{41}$ \\
\hline & . & $0.796^{41}$ & $0.7913^{2 U}$ & $0.7874^{42}$ & $0.7831^{20}$ & $0.7795^{41}$ \\
\hline & $\eta$ & 6.1855 & 5.7347 & 5.302 & 4.9342 & 4.5821 \\
\hline & & $17.302^{41}$ & $15.436^{41}$ & $13.806^{41}$ & $12.392^{41}$ & $11.124^{41}$ \\
\hline \multirow[t]{7}{*}{ 2-Propanol } & $\rho$ & 0.7839 & 0.7797 & 0.7747 & 0.7705 & 0.7659 \\
\hline & & $0.7765^{7}$ & $0.7726^{7}$ & $0.7688^{7}$ & $0.7635^{7}$ & $0.7588^{7}$ \\
\hline & & $0.7769^{38}$ & $0.772559^{23}$ & $0.76413^{39}$ & $0.7636^{39}$ & $0.7589^{39}$ \\
\hline & & $0.77662^{40}$ & $0.77227^{40}$ & & & \\
\hline & $\eta$ & 6.0127 & 5.5252 & 5.1041 & 4.7369 & 4.4352 \\
\hline & & $17.919^{\prime}$ & $15.529^{\prime}$ & $13.554^{\prime}$ & $11.822^{\prime}$ & $10.469^{\prime}$ \\
\hline & & $17.92^{23}$ & $15.5^{23}$ & $13.52^{23}$ & $11.895^{23}$ & $10.468^{23}$ \\
\hline \multirow[t]{5}{*}{ Butanol } & $\rho$ & 0.8045 & 0.7992 & 0.7944 & 0.7915 & 0.7889 \\
\hline & & $0.7941^{36}$ & $0.7901^{36}$ & $0.7876^{36}$ & & \\
\hline & & $0.8042^{3 /}$ & $0.8005^{3 /}$ & & & \\
\hline & $\eta$ & 21.4502 & 18.9692 & 16.5634 & 14.7585 & 13.3124 \\
\hline & & $19.887^{36}$ & $18.528^{36}$ & $15.765^{36}$ & & \\
\hline \multirow[t]{4}{*}{ 1-Pentanol } & $\rho$ & 0.9079 & 0.905 & 0.9005 & 0.8977 & 0.8943 \\
\hline & & $0.8018^{36}$ & $0.7971^{36}$ & $0.7946^{36}$ & & \\
\hline & $\eta$ & 13.3353 & 11.7296 & 10.522 & 9.1756 & 8.3112 \\
\hline & & $26.496^{36}$ & $23.087^{36}$ & $20.753^{36}$ & & \\
\hline
\end{tabular}



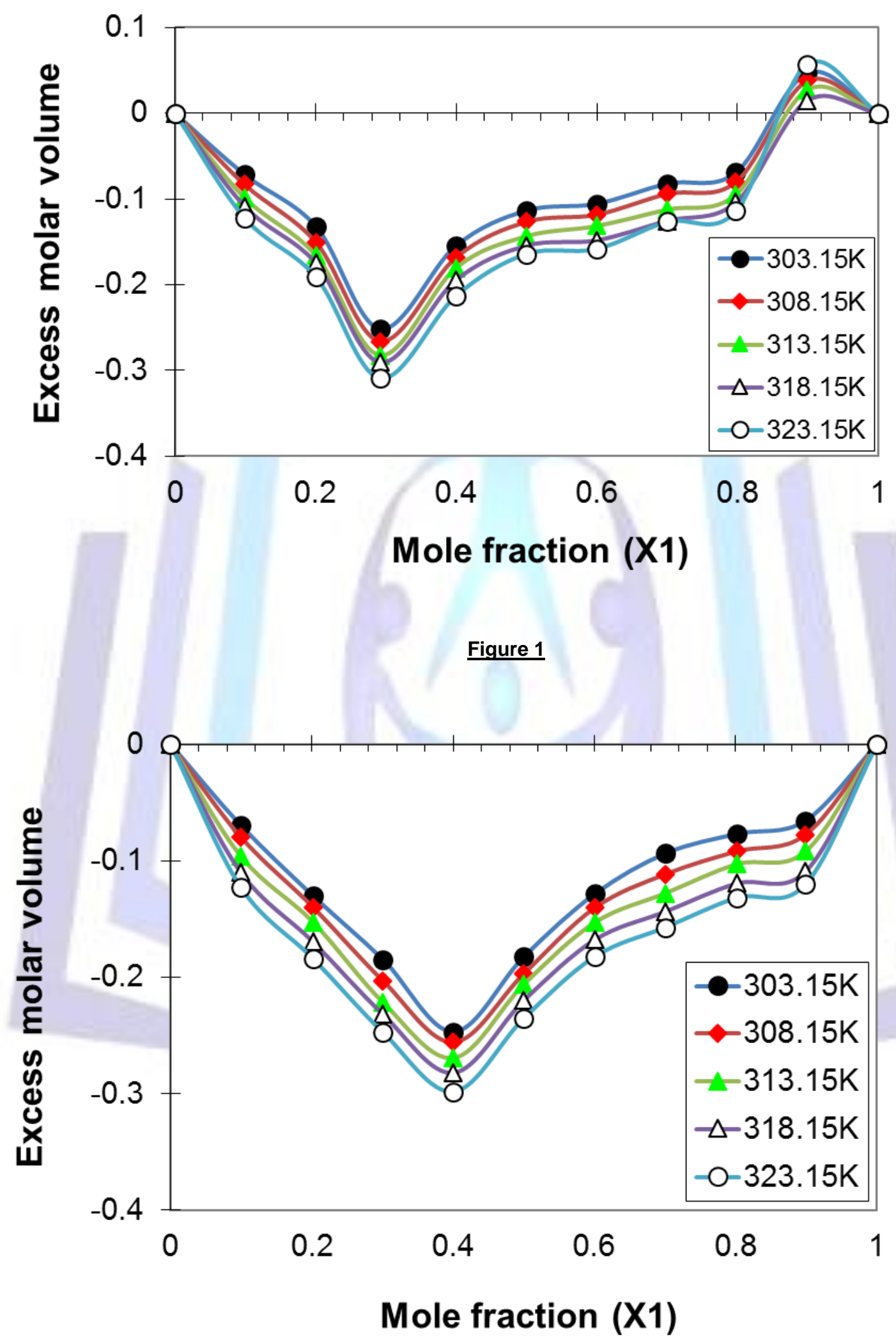

Figure 2 


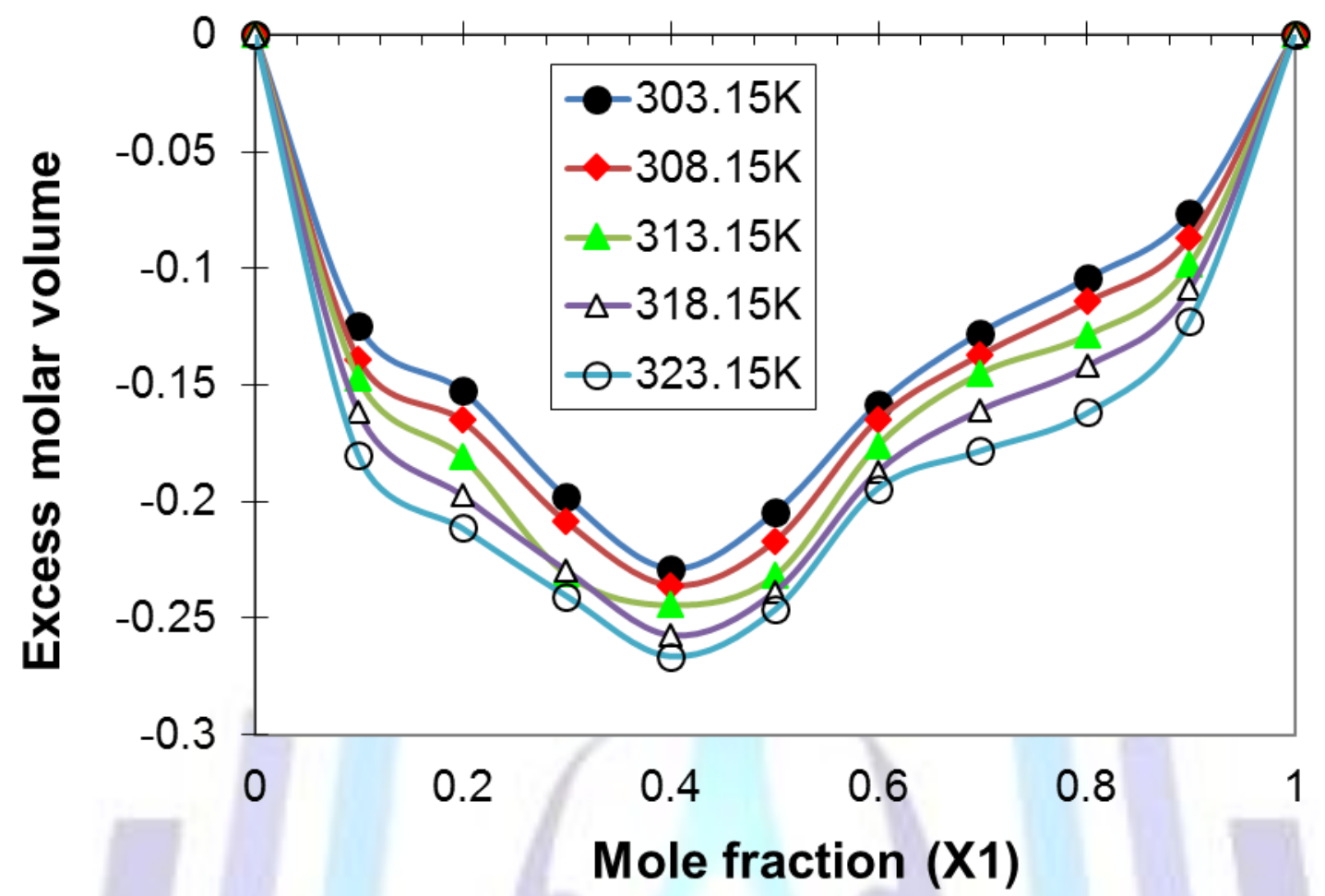

Figure 3

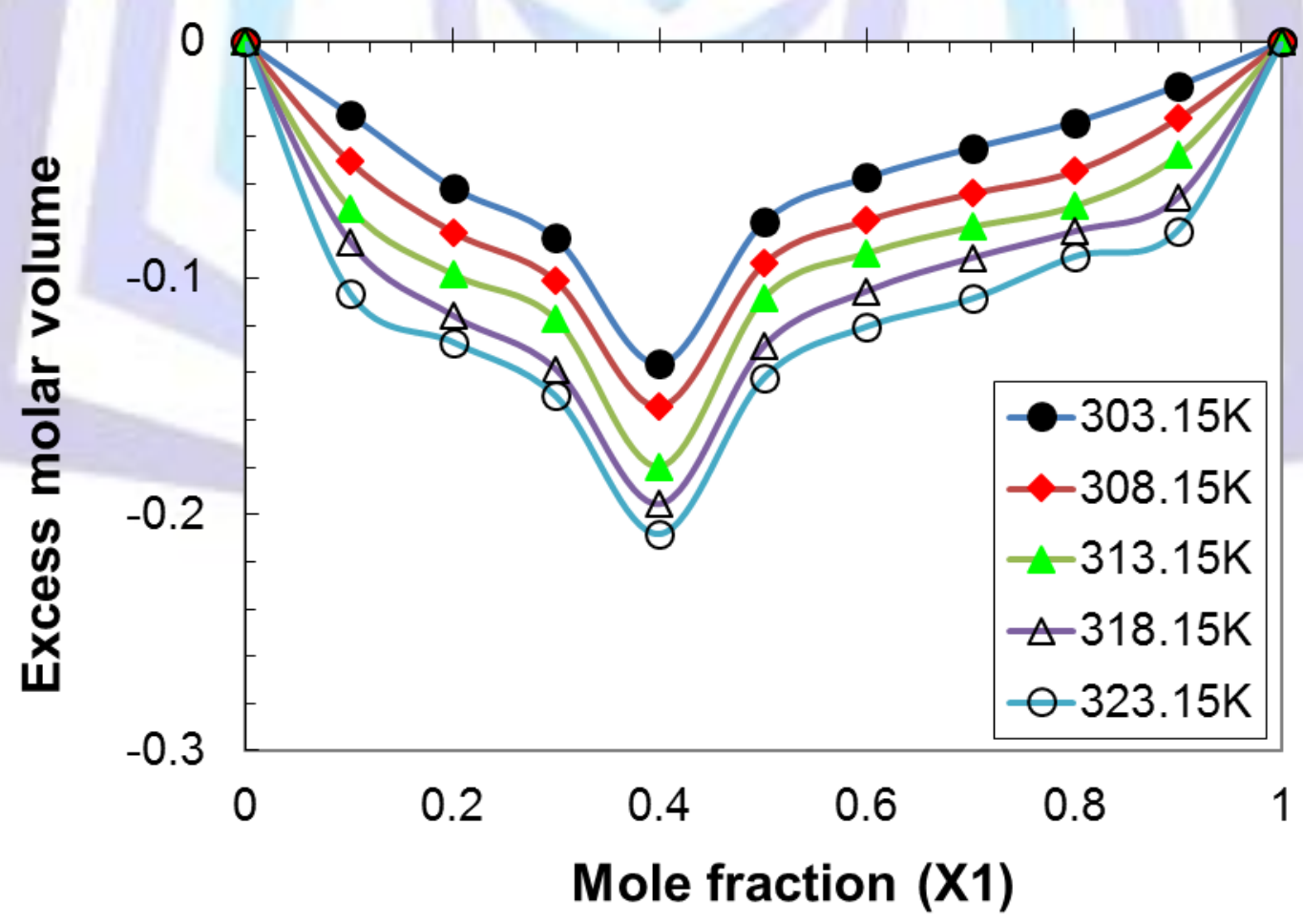

Figure 4 

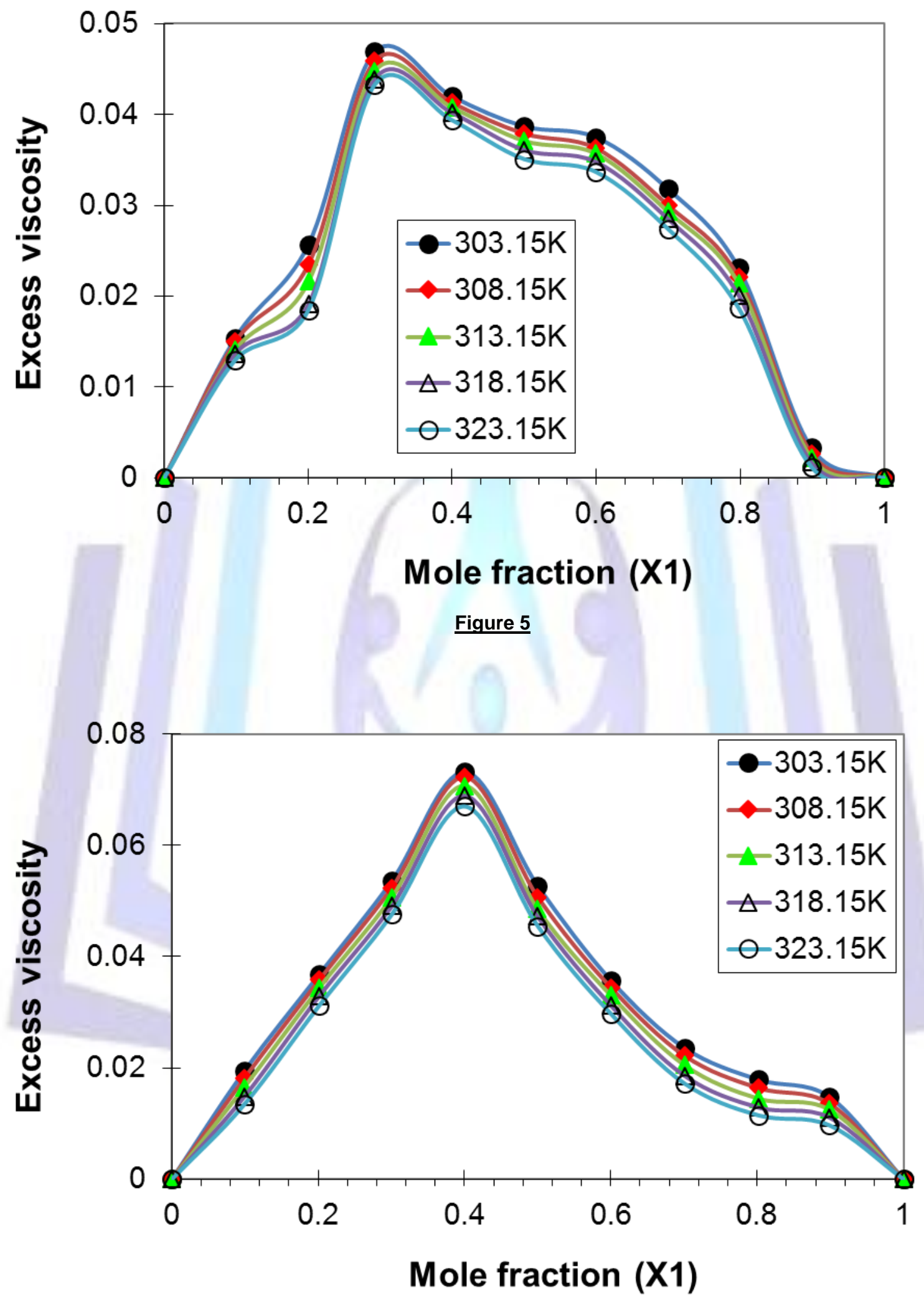

Figure 6 

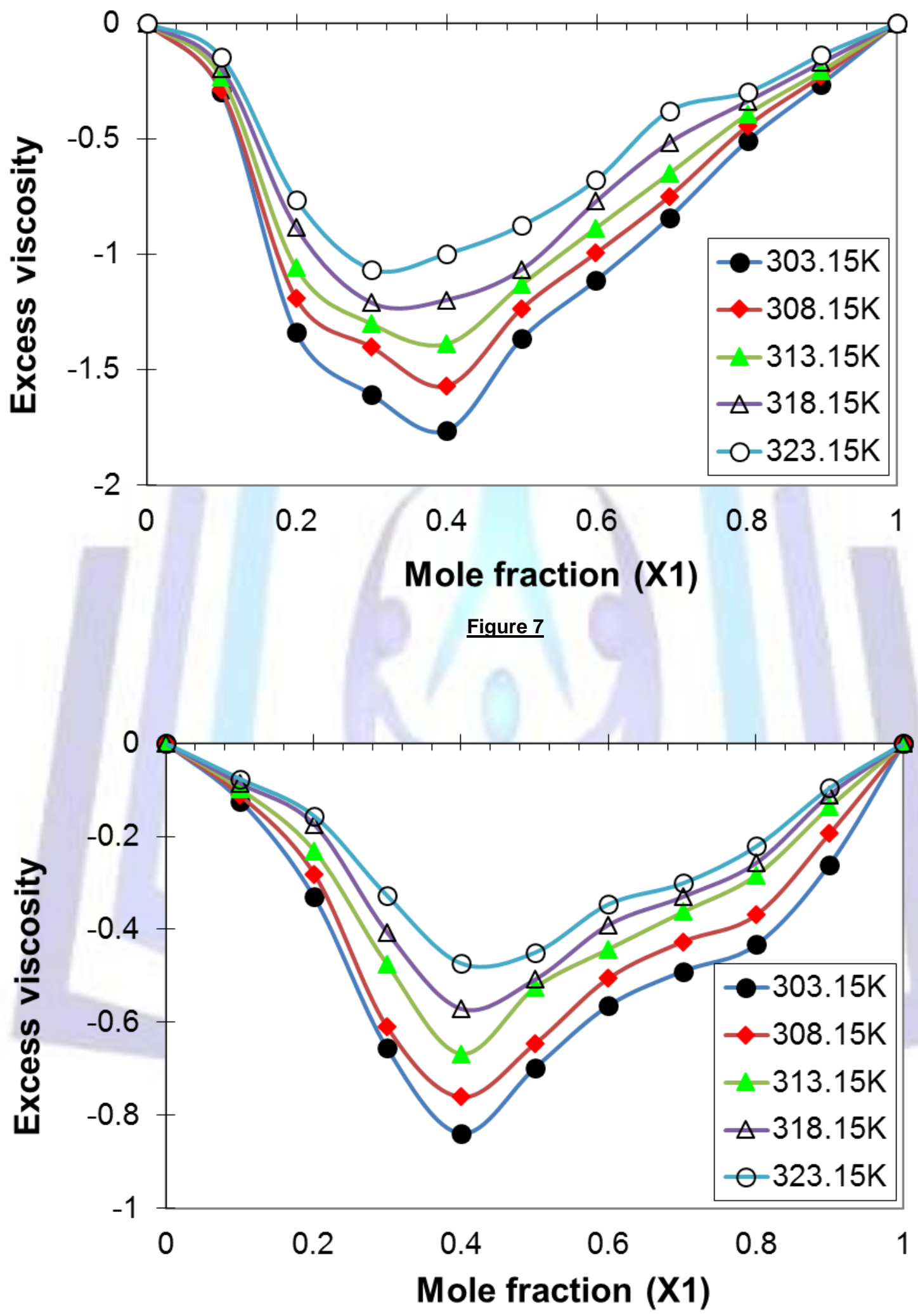

Figure 8 


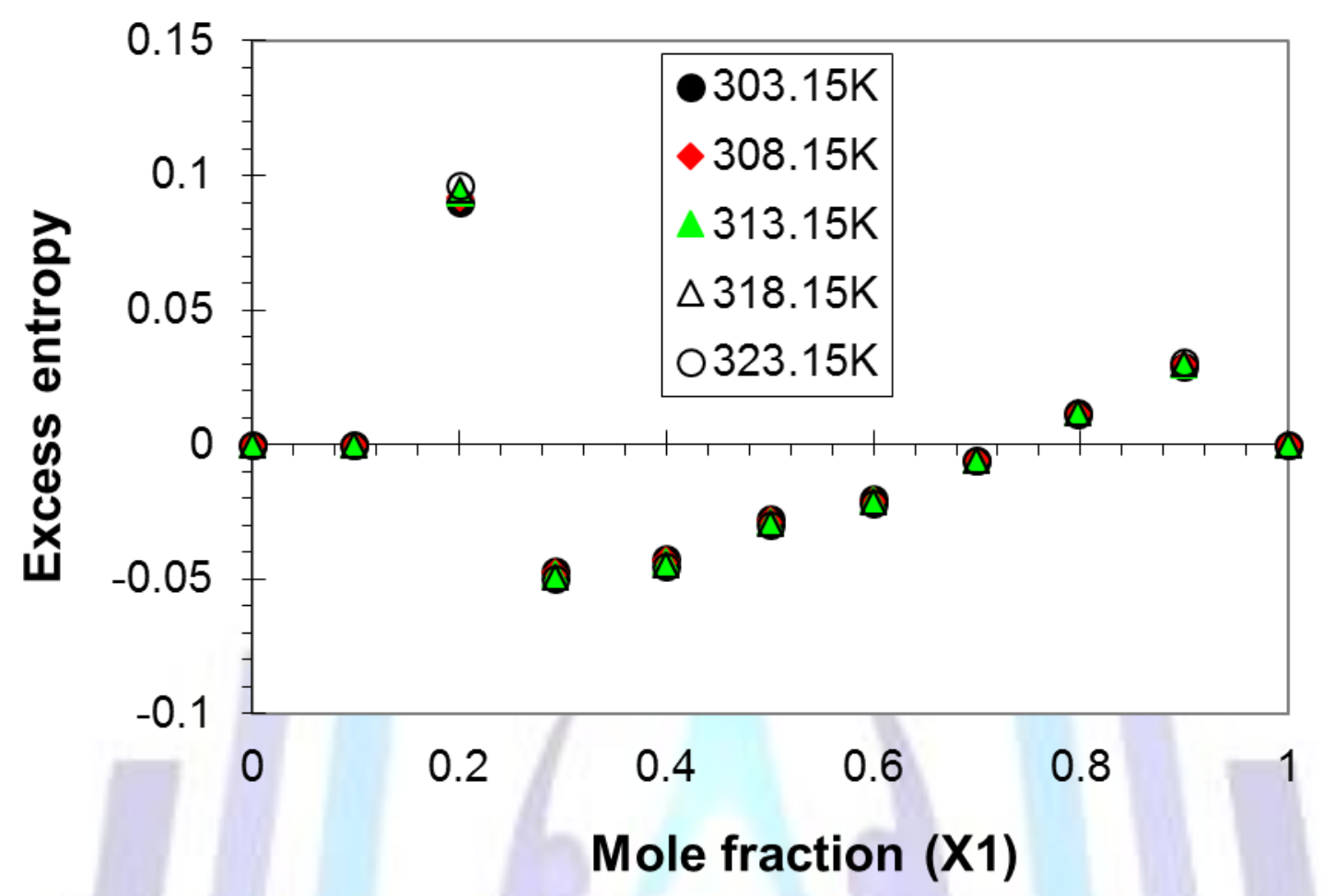

Figure 9

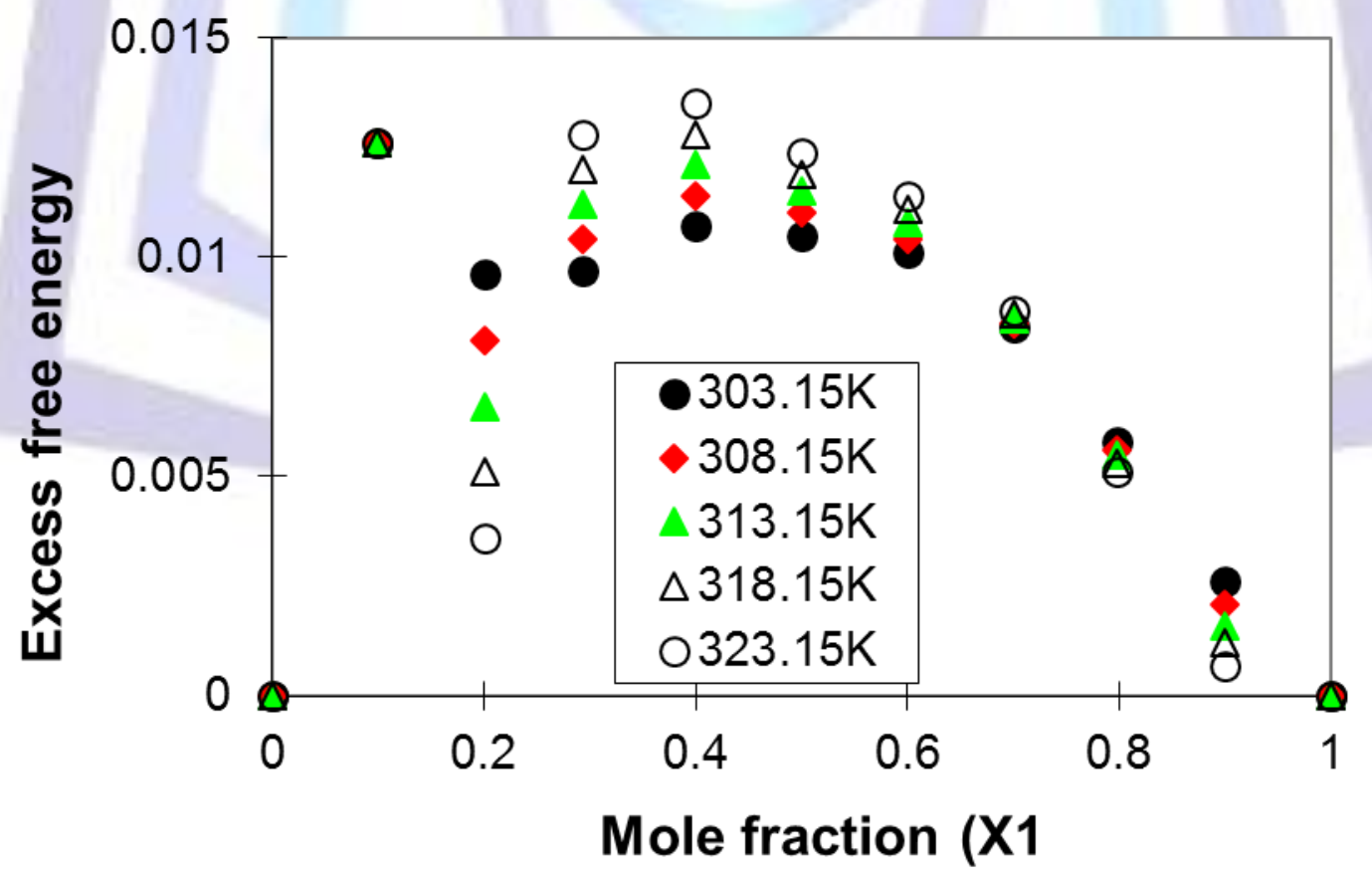

Figure 10 

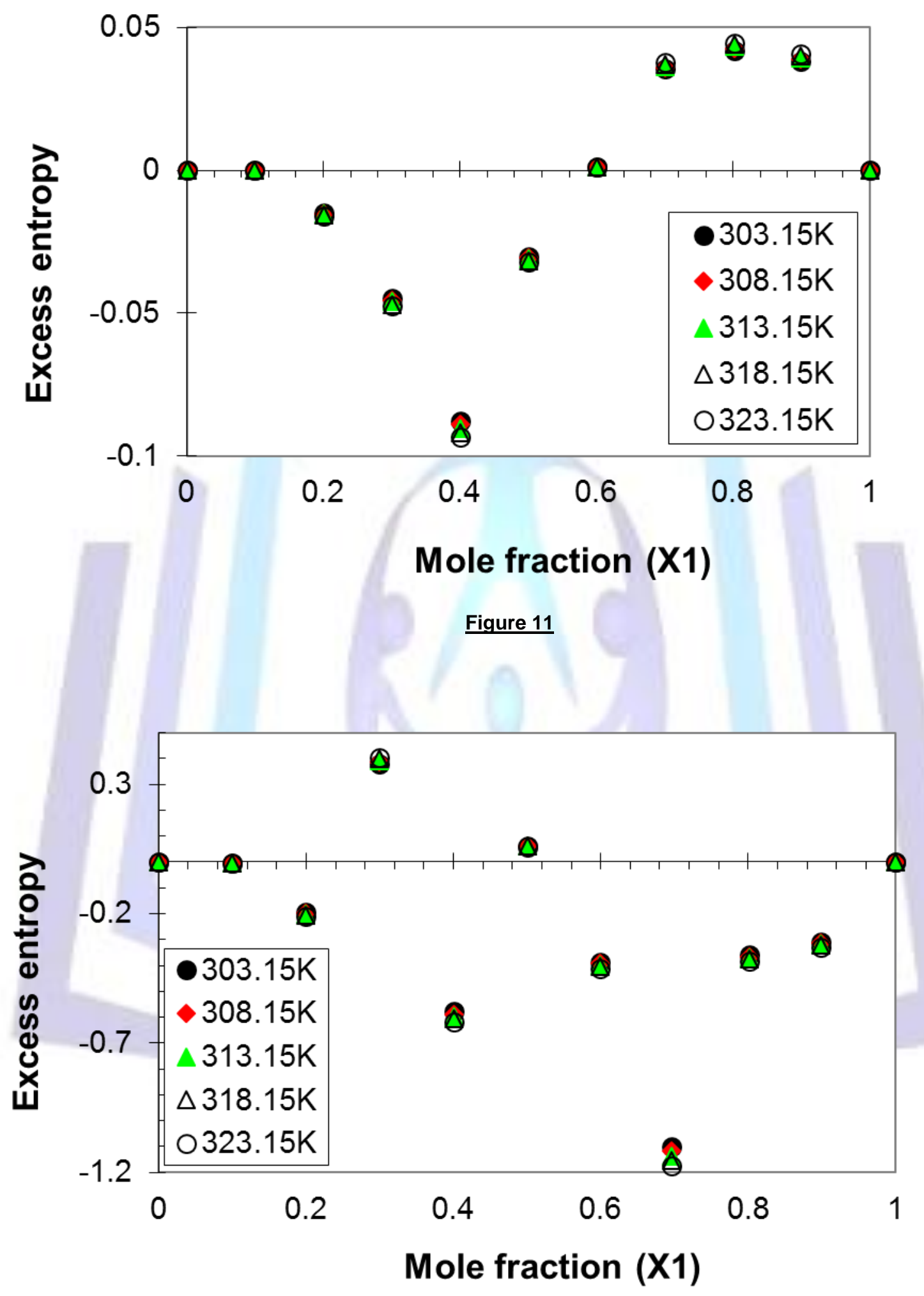

Figure 12 


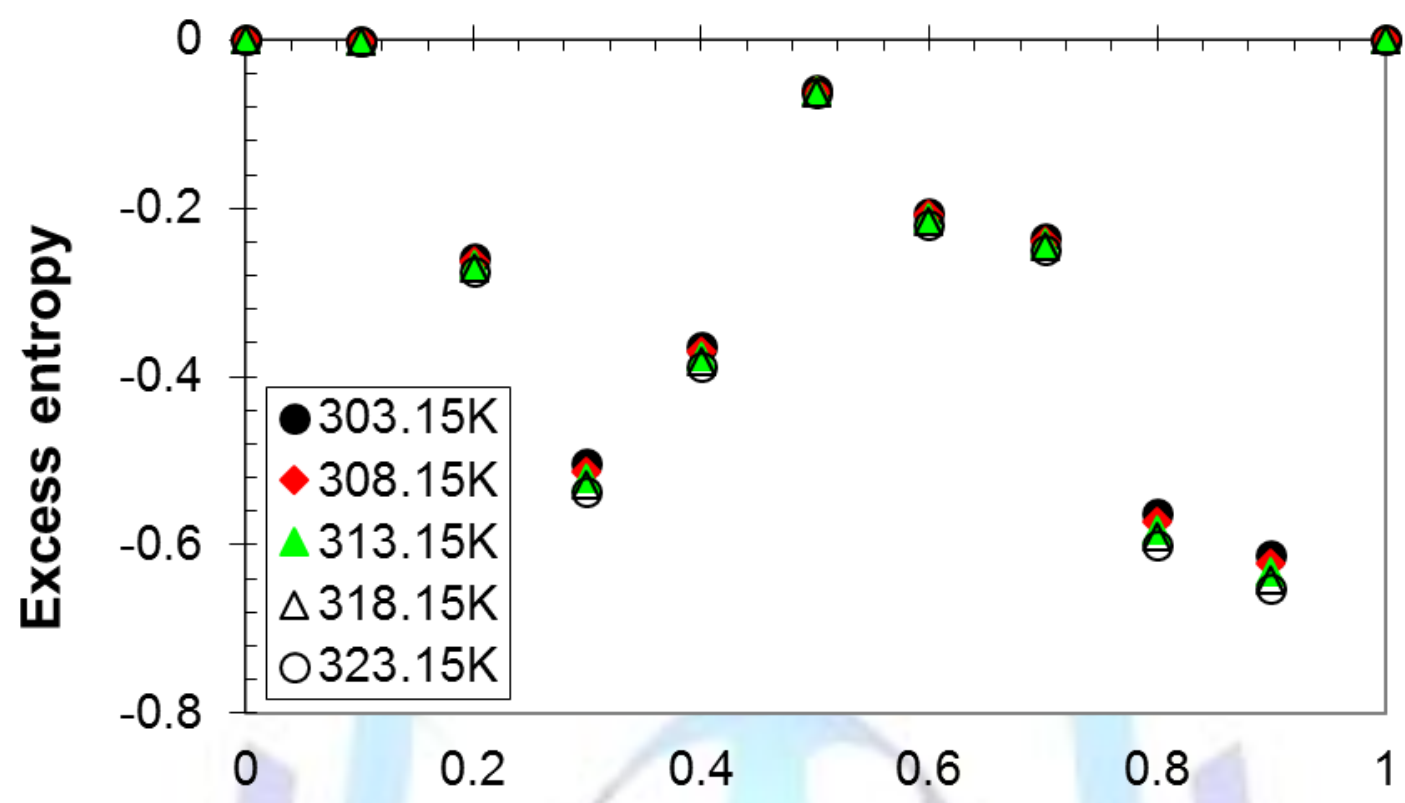

\section{Mole fraction (X1)}

Figure 13

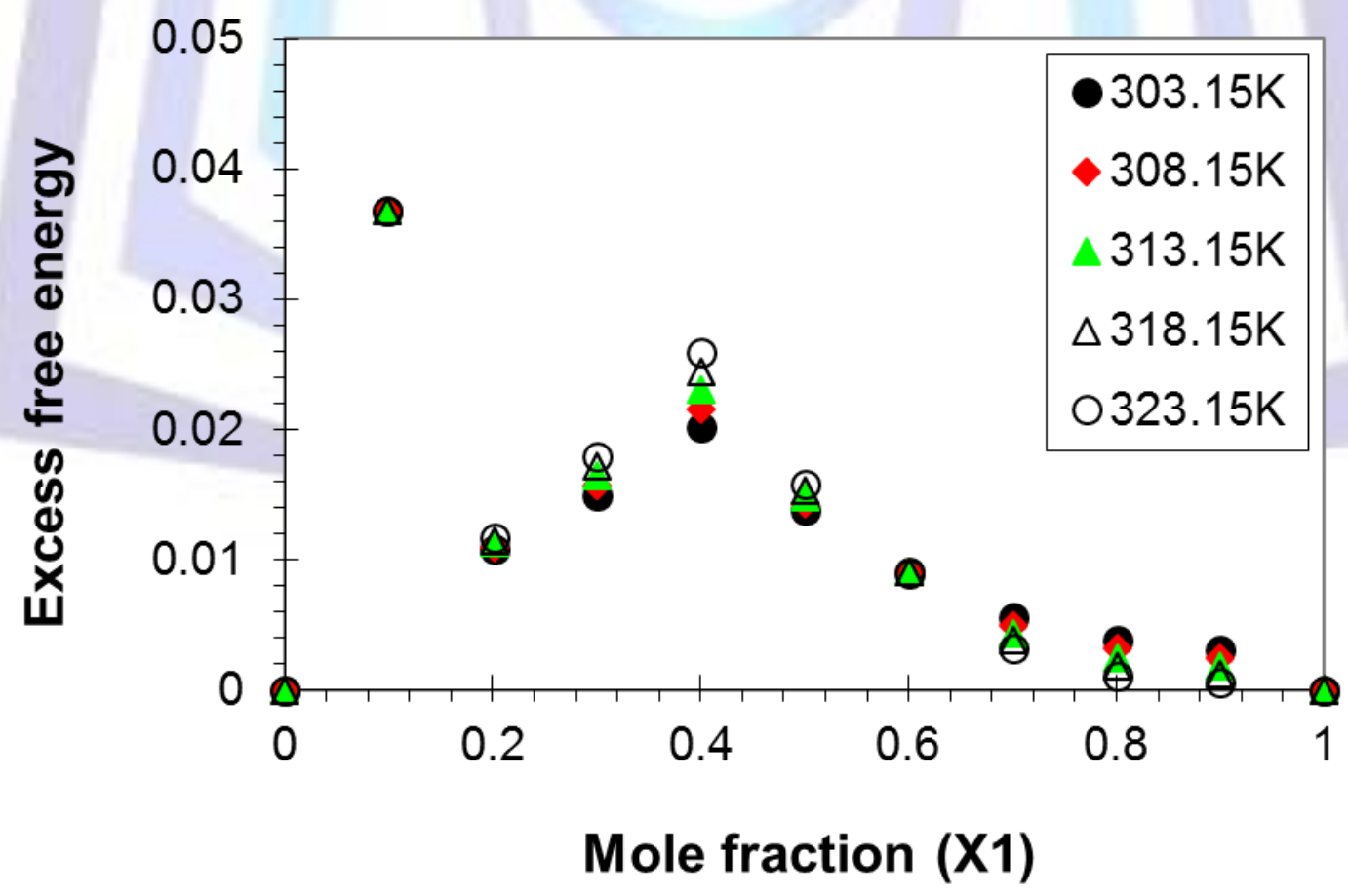

Figure 14 


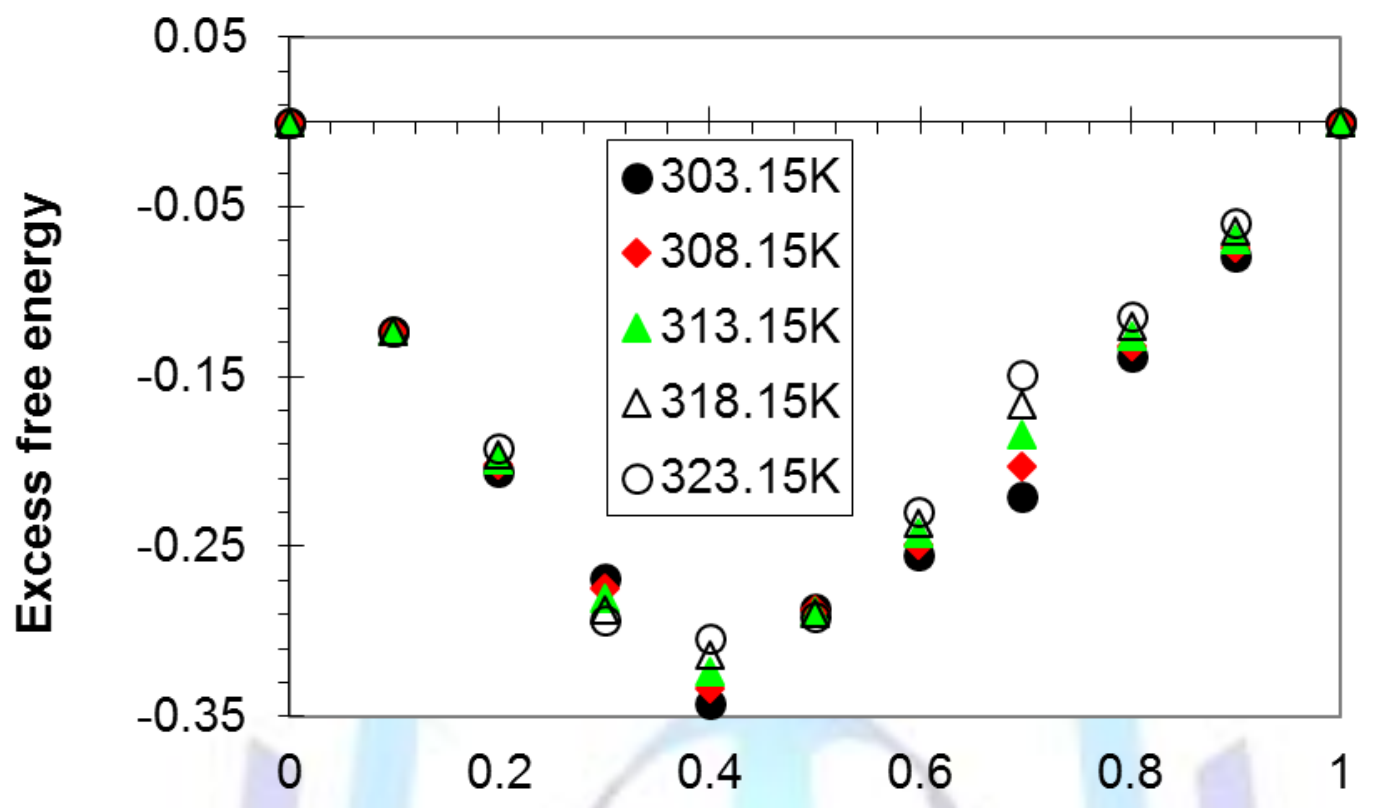

Mole fraction (X1)

Figure 15

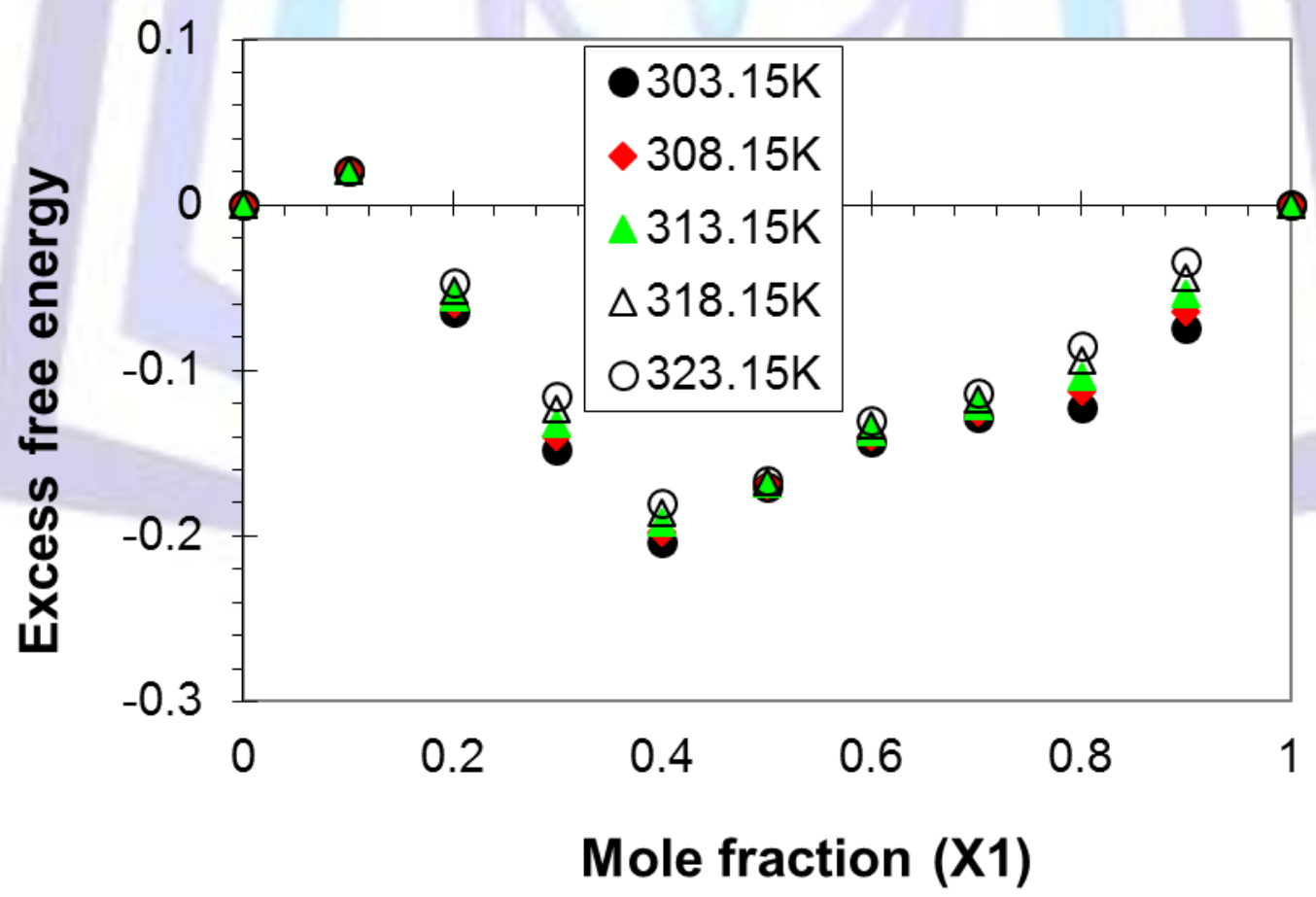

Figure 16 